\title{
27. RECORD LOW NORTHERN HEMISPHERE SEA ICE EXTENT IN MARCH 2015
}

\author{
Neven S. Fučkar, François Massonnet, Virginie Guemas, Javier García-Serrano, Omar Bellprat, \\ Francisco J. Doblas-Reyes, and Mario Acosta
}

\begin{abstract}
The record low Northern Hemisphere (NH) winter sea ice maximum stemmed from a strong interannual surface anomaly in the Pacific sector, but it would not have been reached without long-term climate change.
\end{abstract}

Introduction. Since the late 1970s, the NH sea ice concentration (SIC), age, and thickness in most Arctic regions have experienced long-term decline superimposed with strong internal variability (Stroeve et al. 2012; Jeffries et al. 2013; Comiso and Hall 2014). March NH sea ice extent (SIE: integrated area of grid cells with monthly-mean SIC > 15\%) reached the lowest winter maximum in the satellite record in 2015 (Fig. 27.1a). This extreme of 15.13 million $\mathrm{km}^{2}$ is 1.12 million $\mathrm{km}^{2}$ below the $1980-2015$ average NH March SIE, and 0.33 million $\mathrm{km}^{2}$ below the linear fit over the same period, based on SIC from the EUMETSAT's Satellite Application Facility on Ocean and Sea Ice (OSI SAF; Eastwood 2014).

The March 2015 SIC anomaly pattern in Fig. 27.1d shows that the reduced SIC in the Barents and Greenland Seas is contrasted by the increased SIC in the Baffin Bay and the Labrador Sea leading to the $\mathrm{NH}$ SIE in the Atlantic sector $\left(\mathrm{NH}_{\text {Atl }} \mathrm{SIE}\right)$ of 0.28 million $\mathrm{km}^{2}$ above the linear fit. At the same time, negative SIC anomalies in the Bering Sea and Sea of Okhotsk in Fig. 27.1d pushed the NH SIE in the Pacific sector $\left(\mathrm{NH}_{\mathrm{Pac}} \mathrm{SIE}\right)$ to the record low of 0.61 million $\mathrm{km}^{2}$ below the linear fit, which is outside the $95 \%$ confidence interval of the linear-fit residuals. Hence, the 2015 $\mathrm{NH}_{\mathrm{Pac}}$ SIE strong interannual anomaly contributed most substantially to this NH SIE record low. The spatially nonuniform linear trend of the NH March SIC in Fig. 27.1e yields about three times faster longterm decline of the $\mathrm{NH}_{\mathrm{Atl}}$ SIE than the $\mathrm{NH}_{\text {Pac }}$ SIE.

AFFILIATIONS: FuČKar, Massonnet, Guemas, García-Serrano, Bellprat, ANd Acosta-Barcelona Supercomputing Center-Centro Nacional de Supercomputación (BSC-CNS), Earth Sciences Department, Barcelona, Spain; DoBLAs-ReYES-BSC-CNS, Earth Sciences Department, Barcelona, Spain, and Instituciò Catalana de Recerca i Estudis Avancats, Barcelona, Spain

DOI:10.1175/BAMS-D-16-0153.I

A supplement to this article is available online (10.1175 /BAMS-D-16-0153.2)
The 2015 SIC anomaly pattern with respect to this long-term linear fit (Fig. 27.1f) further indicates that negative interannual anomalies in the Pacific sector outside of the Arctic basin dominate over the positive ones west of Greenland in the Atlantic.

The anomaly and detrended anomaly patterns in Supplemental Fig. S27.1 show anticyclonic sea level pressure over the western Aleutian Islands associated with positive 2-m air temperature over the Sea of Okhotsk in March 2015 likely due to southerly surface wind that substantially contributed to the negative SIC there (Kimura and Wakatsuchi 1999), while the negative SIC in the Bering Sea is more directly related to collocated positive sea surface temperature (SST, Zhang et al. 2010). Such strong interannual surface anomalies in these two marginal seas therefore seem to have played an important role in the NH SIE record low, but what is the role of the underlying long-term change in the ocean and sea ice cover? They integrate the impact of climate change that is pronounced in the high north due to the Arctic amplification (Screen et al. 2012; Taylor et al. 2013). Would the 2014/15 fall-winter atmosphere yield this sea ice extreme if we reversed in time the long-term change in the ocean and sea ice state? We examine the contributions of the atmosphere and the long-term memory of the ocean and sea ice to the March 2015 record low of the NH SIE.

Method. A climate variable can be decomposed into the sum of the background state represented as a linear fit over the period of interest and an interannual anomaly with respect to this fit: $\operatorname{var}(t)=\left[a_{1} t+a_{0}\right]+$ $\operatorname{var}^{\prime}(t)$. To estimate the contributions of the evolution of the ocean and sea ice linear-fit background state over the last 36 years, and the 2014/15 fall-winter atmosphere to the NH March SIE minimum, we perform a set of control and sensitivity experiments 
(a)
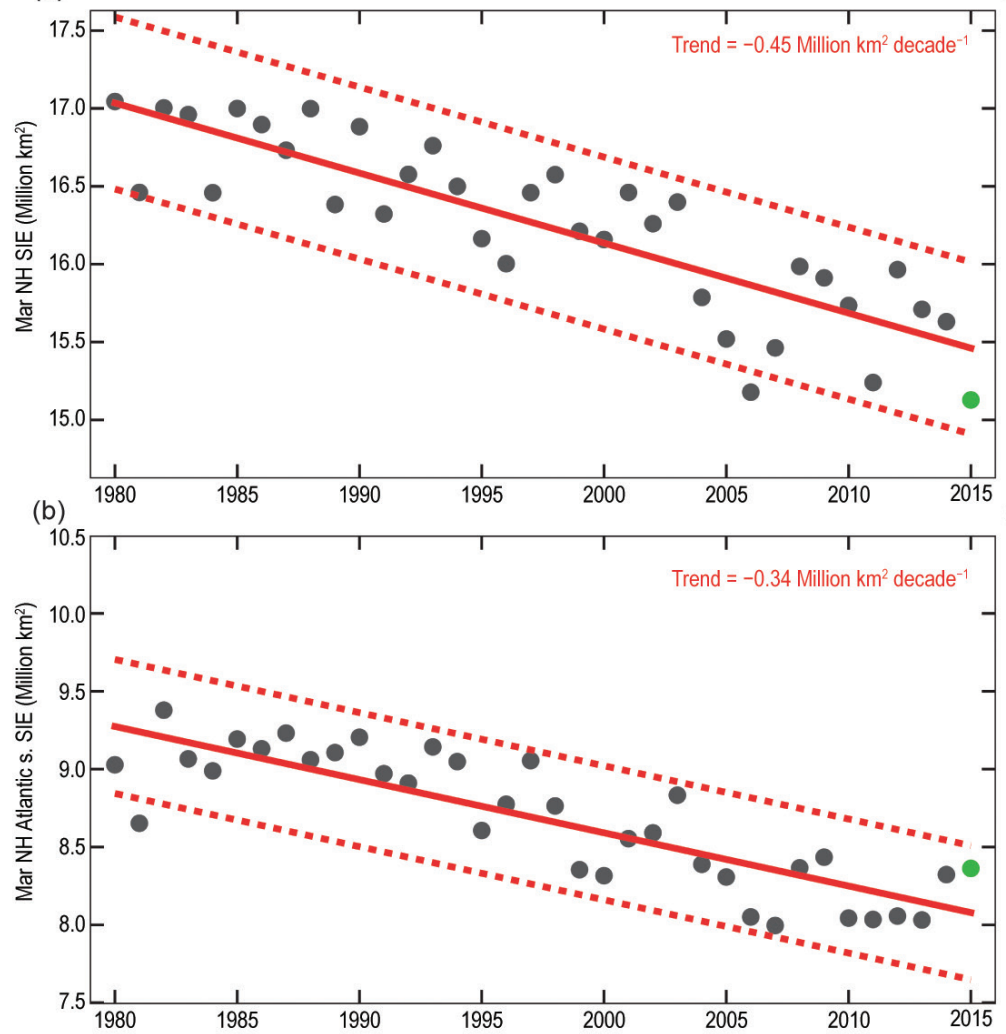

(c)

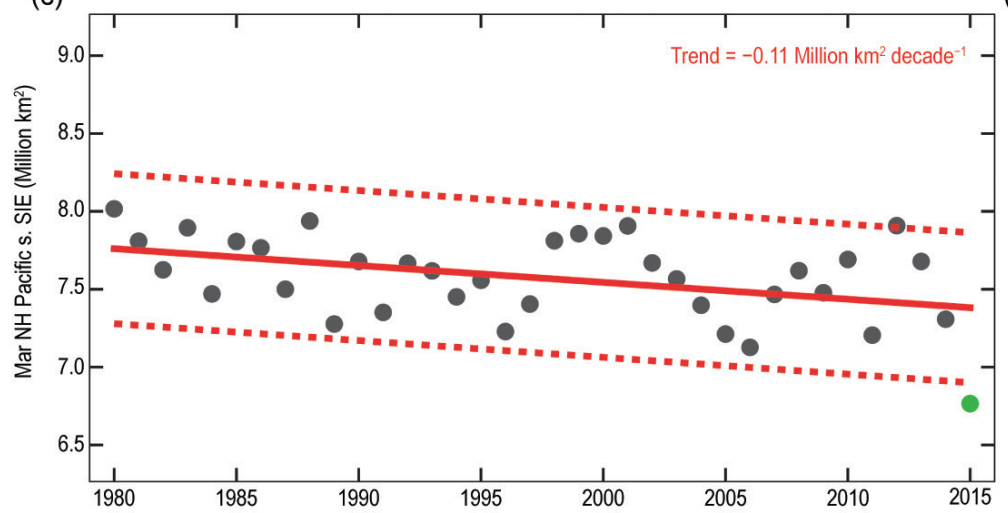

(d)

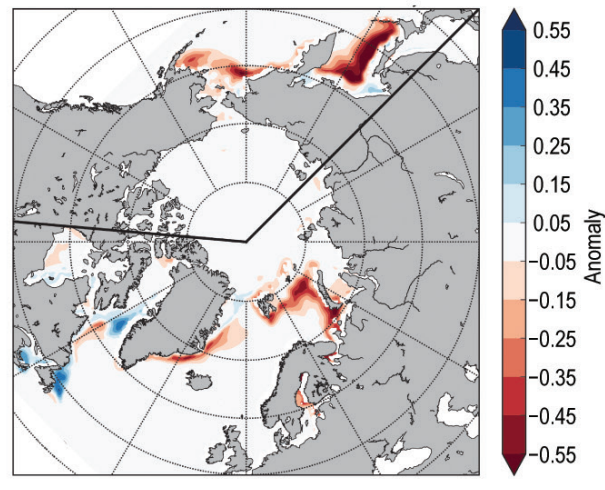

(e)

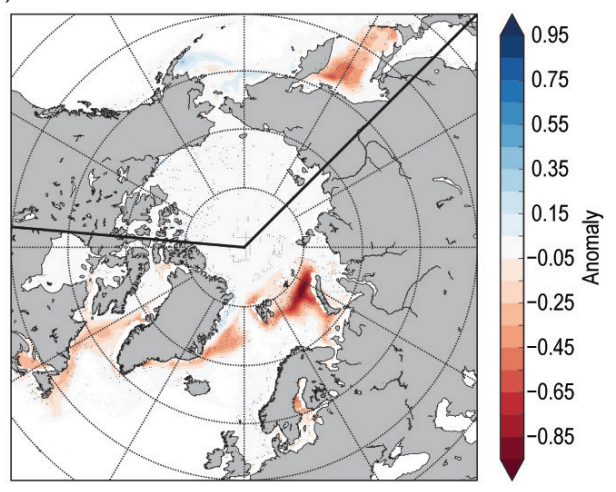

(f)

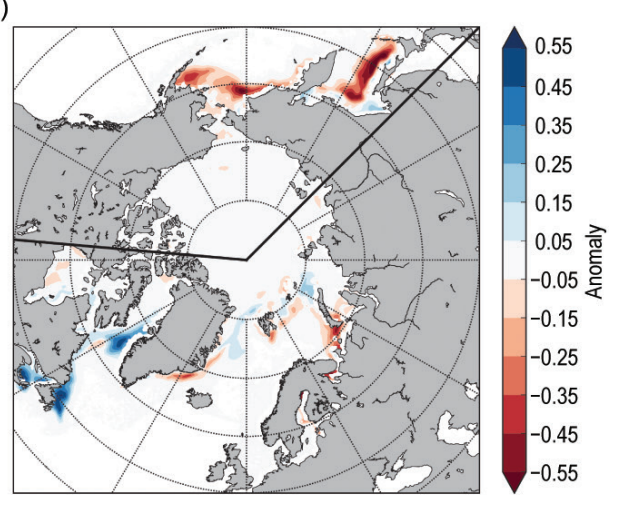

FIG. 27.I. (a)-(c) Black points show the total SIE, SIE in the Atlantic sector (from $95^{\circ} \mathrm{W}$ to $135^{\circ} \mathrm{E}$ ), and $\mathrm{SIE}$ in the Pacific sector (from $135^{\circ} \mathrm{E}$ to $265^{\circ} \mathrm{E}$ ) in the NH in Mar from 1980 to 2015 (which is exclusively marked in green), respectively, from OSI SAF. Solid (dashed) red lines show the linear fit with trends indicated in the upper right corner (the $95 \%$ confidence interval of the residuals of the linear fit). (d)-(f) The NH SIC anomaly in Mar 2015 with respect to the 1980-2015 average, linear change (linear trend times 36 years) where stippling denotes 5\% significance, and anomaly in Mar 2015 with respect to the linear fit over this period, respectively.

with a state-of-the-art ocean-sea ice general circulation model (OGCM). We utilize NEMO3.3-LIM3 OGCM (Madec et al. 2008; Vancoppenolle et al., 2009) forced by the ECMWF's ERA-Interim atmospheric reanalysis (Dee et al. 2011) as described in Massonnet et al. (2015)

First, we perform a set of 5-month-long retrospective control simulations (CTL) initialized on 1 November from 1979 to 2014 to assess the model skill in predicting the NH March SIE. We produce five ensemble members initialized from the five members of the ECMWF's Ocean Reanalysis System 4 (ORAS4; Balmaseda et al. 2013) and the associated five-member sea ice reconstruction produced with the same OGCM through the restoring methodology described in Guemas et al. (2014). CTL in March have 3.0, 2.4, and 5.5 times weaker ensemble-mean downward trends (along the start dates) than OSI SAF 
in the $\mathrm{NH}, \mathrm{NH}_{\mathrm{Atl}}$, and $\mathrm{NH}_{\mathrm{Pac}}$ SIE, respectively (see online supplemental material). Hence, we apply the trend bias correction method (Kharin et al. 2012; Fučkar et al. 2014) to obtain adjusted March 2015 forecasts of the $\mathrm{NH}, \mathrm{NH}_{\mathrm{Atl}}$, and $\mathrm{NH}_{\mathrm{Pac}} \mathrm{SIE}$ ensemble means of 15.09 million $\mathrm{km}^{2}, 8.22$ million $\mathrm{km}^{2}$, and 6.86 million $\mathrm{km}^{2}$ (Figs. 27.2a, 27.2b, and 27.2c), respectively. CTL ensemble shows overconfidence, likely due to the small ensemble as well as missing physical processes, such as multicategory sea ice and interactive atmosphere. Small ensemble-mean errors in 2015 (less than 2\% in each domain) indicate that the adjusted OGCM forecasts have appropriate skill for our analysis.

Next, we conduct two sets of four five-member sensitivity experiments with initial conditions (IC) and surface forcing fields specified in Table 27.1. In general, the forced OGCM forecast of the March state evolves from a past state to the 2015 state due to modifications in IC and forcing fields that can be decomposed into: (i) linearfit background state of IC; (ii) interannual anomaly in IC with respect to factor (i); (iii) linear-fit background state of surface forcing fields; and (iv) interannual anomaly in surface forcing fields with respect to factor (iii). The experiments e $82^{*}, \mathrm{e} 92^{*}, \mathrm{e} 02^{*}$, and $\mathrm{e} 12^{*}$ forecast the March state for four different years (1982, 1992, 2002, and 2012), starting from the ocean and sea ice IC on 1 November 1981, 1991, 2001, and 2011, respectively, with modified factor (ii). Specifically, we replace a past interannual anomaly of IC with the 1 November 2014 (20141101) IC anomaly (all calculated with respect to the 1979-2014 linear fit of 1 November ocean and sea ice IC). The experiments e82 through
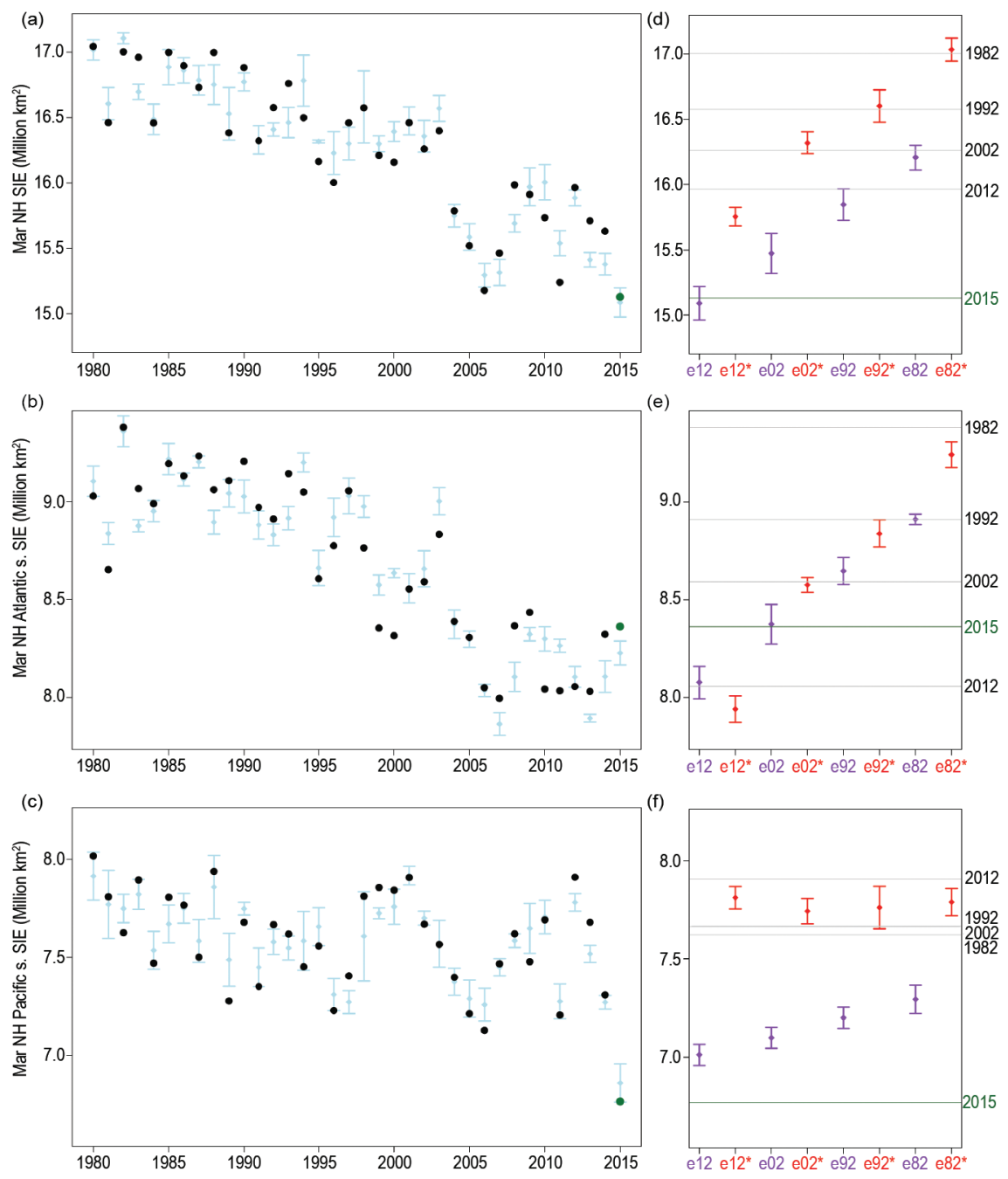

FIG. 27.2. (a)-(c) Full black circles (full light blue diamonds with the $95 \%$ confidence interval bars) show the total SIE, SIE in the Atlantic sector, and SIE in the Pacific sector in the NH in Mar from 1980 to 2015, respectively, from OSI SAF (NEMO3.3-LIM3 adjusted CTL values). (d)-(f) The total SIE, SIE in the Atlantic sector, and SIE in the Pacific sector of the NH in Mar, respectively, of adjusted sensitivity experiments (means with the $95 \%$ confidence interval bars). Horizontal lines in the right panels indicate OSI SAF Mar NH SIE for the same domains (left) for the years indicated on the right.

e12 examine how much the selected March forecasts would change further if we use the same IC as in e82* through e12*, respectively, but also modify both factors (iii) and (iv): We apply the 2014/15 fall-winter surface forcing fields in e82 through e12.

Results. The adjusted $\mathrm{e} 82^{\star}$ through $\mathrm{e} 12^{\star}$ March forecasts enable us to examine the contribution of 20141101 interannual IC anomaly to the total change between the selected past years and 2015 through the ratios: [CTL(1982) - e82*] / [CTL (1982) - CTL(2015)], ..., $\left[\mathrm{CTL}(2012)-\mathrm{e} 12^{*}\right] /[\mathrm{CTL}(2012)-\mathrm{CTL}(2015)]$. 


\begin{tabular}{|c|c|c|}
\hline \multicolumn{3}{|c|}{$\begin{array}{l}\text { Table } 27 . \text {. Summary of the determining characteristics } \\
\text { of each sensitivity experiment and the associated control } \\
\text { experiments. }\end{array}$} \\
\hline Name & $\begin{array}{l}\text { Global ocean and sea ice IC } \\
\text { linear fit + interannual } \\
\text { anomaly (yyyymmdd) }\end{array}$ & $\begin{array}{l}\text { Surface forcing fields } \\
\text { start-end } \\
\text { (yyyymm) }\end{array}$ \\
\hline & (ii) & (iii) and (iv) \\
\hline CTL(1982) & lin.fit(I98III0I) + anom.(I98IIIOI) & $19811 \mid-198203$ \\
\hline e82* & lin.fit(198III0I) + anom.(2014II0I) & $19811 \mid-198203$ \\
\hline e82 & lin.fit(I98IIIOI) + anom.(20I4II0I) & $20|4| I-201503$ \\
\hline CTL(1992) & lin.fit(I99III0I) + anom.(I99III0I) & $199111-199203$ \\
\hline e92* & lin.fit(199III0I) + anom.(2014II0I) & $199111-199203$ \\
\hline e92 & lin.fit(I99III0I) + anom.(2014II0I) & $201411-201503$ \\
\hline CTL(2002) & lin.fit(200III0I) + anom.(200III0I) & $200111-200203$ \\
\hline e02* & lin.fit(200IIIOI) + anom.(20I4II0I) & $200111-200203$ \\
\hline e02 & lin.fit(200III0I) + anom.(20I4II0I) & $201411-201503$ \\
\hline CTL(20I2) & lin.fit(20IIIIOI) + anom.(20IIIIOI) & $2011111-201203$ \\
\hline el2* & lin.fit(20IIIIOI) + anom.(20I4II0I) & $201111-201203$ \\
\hline el2 & lin.fit(20IIIIOI) + anom.(20I4IIOI) & $20|4| I-201503$ \\
\hline & (ii) & (iii) and (iv) \\
\hline CTL(20I5) & lin.fit(20I4IIOI) + anom.(20I4II0I) & $20|4| \mid-201503$ \\
\hline
\end{tabular}

past-2015 change of $61.9 \%, 54.1 \%$, and $74.1 \%$ (on average between these sensitivity experiments) in the $\mathrm{NH}$, $\mathrm{NH}_{\mathrm{Atl}}$, and $\mathrm{NH}_{\mathrm{Pac}}$ SIE, respectively. Experiments e82 through e12 still contain the background IC state of the past years that typically prevents them from reaching the 2015 record (purple symbols are mostly far from the CTL 2015 values on the right in Fig. 27.2). The linear-fit slopes of the March forecasts from e82 to e12 of the $\mathrm{NH}, \mathrm{NH}_{\mathrm{Att}}$, and $\mathrm{NH}_{\mathrm{Pac}}$ SIE have values of $0.37,0.28$, and 0.09 million $\mathrm{km}^{2} 10-\mathrm{yr}^{-1}$, respectively. They show that the long-term linear change of the ocean and sea ice background state plays an important role, even in the Pacific sector (Fig. 27.2f) where the long-term trend is the weakest.

Conclusions. The performed experiments indicate that the most important factor driving the $\mathrm{NH}$ SIE to the record low in March 2015 was surface atmospheric conditions on average contributing at least $54 \%$ to the change from the past March states. The 1 November 2014 interannual anomaly of IC, which on average contributes less than $10 \%$, is the least important factor. A change along the 36-year linear-fit of IC, representing the accumulative

The recent interannual anomaly in the ocean and sea ice IC explains a minor part of the total past-2015 change of the $\mathrm{NH}, \mathrm{NH}_{\mathrm{Atl}}$, and $\mathrm{NH}_{\mathrm{Pac}}$ SIE: $2.1 \%, 9.0 \%$, and $-9.9 \%$ on average from e $82^{\star}$ to $122^{\star}$, respectively (red symbols on the right in Fig. 27.2 are close to the associated CTL forecasts on the left). The linear regressions of the March forecasts from e $82^{*}$ to $\mathrm{e} 12^{*}$ of the $\mathrm{NH}, \mathrm{NH}_{\mathrm{Atl}}$, and $\mathrm{NH}_{\mathrm{Pac}}$ SIE have significant slopes of $0.41,0.42$, and -0.01 million $\mathrm{km}^{2} 10-\mathrm{yr}^{-1}$, respectively.

The experiments e 82 through e 12 compared with experiments e $82^{*}$ through $\mathrm{e} 12^{*}$, respectively, examine the contributions of 2014/15 fall-winter surface forcing fields to the total change between the selected past years and 2015 through the ratios: $\left(e 82^{*}-\mathrm{e} 82\right)$ / [CTL(1982) - CTL(2015)], ... and (e12* - e12) / [CTL(2012) - CTL(2015)]. This change in both (iii) and (iv) makes the dominant contribution to the total impact of the climate change in the ocean and sea ice, is the second most important factor for attaining the March 2015 extreme in our experiments. Even if we keep IC and forcing factors (ii) through (iv) in the 2014-15 conditions, but translate the background state of ocean and sea ice, IC factor (i), more than three years into the past (in e02, e92, and e82), it prevents our OGCM from reaching this record low. We conclude that March 2015 interannual surface anomalies in the Sea of Okhotsk and the Bering Sea are necessary transient, but not sufficient, conditions to achieve the record low of the NH SIE maximum in March 2015 without underlying climate change.

ACKNOWLEDGEMENTS. Fučkar and Massonnet are Juan de la Cierva fellows. Guemas, García-Serrano and Bellprat are Ramón y Cajal, Marie Curie, and ESA fellows, respectively. This study was supported by 
the funding from the EU's SPECS (308378), EUCLEIA (607085) and PRIMAVERA (641727) projects. The authors thank the editor and reviewers for constructive input and acknowledge the computer resources, technical expertise, and assistance provided by the Red Española de Supercomputación (RES) network and the Barcelona Supercomputing Center.

\section{REFERENCES}

Balmaseda, M. A., K. Mogensen, and A. T. Weaver, 2013: Evaluation of the ECMWF ocean reanalysis system ORAS4. Quart. J. Roy. Meteor. Soc., 139 1132-1161, doi:10.1002/qj.2063.

Comiso, J. C., and D. K. Hall, 2014: Climate trends in the Arctic as observed from space. Wiley Interdiscip. Rev.: Climate Change, 5, 389-409, doi:10.1002 /wcc. 277.

Dee, D. P., and Coauthors, 2011: The ERA-interim reanalysis: Configuration and performance of the data assimilation system. Quart. J. Roy. Meteor. Soc., 137, 553-597, doi:10.1002/qj.828.

Eastwood, S., Ed., 2014: Sea ice product user's manual. Ocean and Sea Ice Satellite Application Facility, 38 pp. [Available online at http://osisaf.met.no/docs /osisaf_ss2_pum_ice-conc-edge-type_v3p11.pdf.]

Fučkar, N. S., D. Volpi, V. Guemas, and F. J. DoblasReyes, 2014: A posteriori adjustment of near-term climate predictions: Accounting for the drift dependence on the initial conditions. Geophys. Res. Lett. 41, 5200-5207, doi:10.1002/2014GL060815.

Guemas, V., F. J. Doblas-Reyes, K. Mogensen, Y. Tang, and S. Keeley, 2014: Ensemble of sea ice initial conditions for interannual climate predictions. Climate Dyn., 43, 2813-2829, doi:10.1007/s00382-014-2095-7.

Jeffries, M. O., J. E. Overland, and D. K. Perovich, 2013: The Arctic shifts to a new normal. Phys. Today, 66 35-40, doi:10.1063/PT.3.2147.

Kimura, N., and M. Wakatsuchi, 1999: Processes controlling the advance and retreat of sea ice in the Sea of Okhotsk. J. Geophys. Res., 104, 11137-11150, doi:10.1029/1999JC900004.

Kharin, V. V., G. J. Boer, W. J. Merryfield, J. F. Scinocca, and W. S. Lee, 2012: Statistical adjustment of decadal predictions in a changing climate. Geophys. Res. Lett., 39, L19705, doi:10.1029/2012GL052647.

Madec, G., and Coauthors, 2008 : NEMO ocean engine. Note du Pôle de modélisation de l'Institut PierreSimon Laplace No 27, 357 pp. [Available online at www.nemo-ocean.eu/About-NEMO/Reference -manuals.]
Massonnet, F., V. Guemas, N. S. Fučkar, F. J DoblasReyes, 2015: The 2014 high record of Antarctic sea ice extent [in "Explaining Extreme Events of 2014 from a Climate Perspective”]. Bull. Amer. Meteor. Soc., 96 (12), S163-S167, doi:10.1175/BAMS-D-15-00093.1.

Screen, J. A., C. Deser, and I. Simmonds, 2012: Local and remote controls on observed Arctic warming. Geophys. Res. Lett., 39, L10709, doi:10.1029/2012GL051598.

Stroeve, J. C., M. C. Serreze, M. M. Holland, J. E. Kay, J. Malanik, and A. P. Barrett, 2012: The Arctic's rapidly shrinking sea ice cover: A research synthesis. Climatic Change, 110, 1005-1027, doi:10.1007/s10584 -011-0101-1.

Taylor, P. C., M. Cai, A. Hu, J. Meehl, W. Washington, and G. J. Zhang, 2013: A decomposition of feedback contributions to polar warming amplification. J. Climate, 26, 7023-7043, doi:10.1175 /JCLI-D-12-00696.1.

Vancoppenolle, M., T. Fichefet, H. Goosse, S. Bouillon, G. Madec, and M. A. Morales Maqueda, 2009: Simulating the mass balance and salinity of Arctic and Antarctic sea ice. 1. Model description and validation. Ocean Modell., 27, 33-53, doi:10.1016/j .ocemod.2008.10.005.

Zhang, J., R. Woodgate, and R. Moritz, 2010: Sea ice response to atmospheric and oceanic forcing in the Bering Sea. J. Phys. Oceanogr., 40, 1729-1747, doi:0.1175/2010JPO4323.1. 